\title{
The Effect of Saffron (Crocus sativus) Carotenoids on Hemostasis and Atherosclerosis
}

\author{
Zacharias M Sinakosa ${ }^{1}$ and George D Geromichalosb ${ }^{2 *}$ \\ ${ }^{1}$ Aristotelian University of Thessaloniki, Thessaloniki, Greece \\ ${ }^{2}$ Department of Cell Culture, Molecular Modeling and Drug Design, Symeonidion Research Center, Theagenion Cancer Hospital, Thessaloniki, Greece
}

"Corresponding author: George D Geromichalosb, Department of Cell Culture, Molecular Modeling and Drug Design, Symeonidion Research Center, Theagenion Cancer Hospital, Thessaloniki, Greece, Tel: +302313301111; E-mail: geromchem@yahoo.gr

Rec date: Apr 21, 2016; Acc date: June 29, 2016; Pub date: June 30, 2016

Copyright: (c) 2016 Geromichalosb GD, et al. This is an open-access article distributed under the terms of the Creative Commons Attribution License, which permits unrestricted use, distribution, and reproduction in any medium, provided the original author and source are credited.

\begin{abstract}
In current review is described in short the findings indicating that Crocus sativus exerts antithrombotic and antiatherosclerosis effect. Summarily, these findings include the documented antioxidant activity of C. sativus on LDL oxidation leading to the initiation of atherosclerosis, its inhibitory effect on the expression of cell adhesion molecules and the adhesion of leucocytes to endothelial cells. Additionally, C. sativus contributes in the inhibition of platelet aggregation, inhibiting coagulation factor Xa and COX-1 (in vitro and in silico studies). All these activities contribute to the inhibition of the progression of atherosclerosis.
\end{abstract}

Keywords: Saffron; Antithrombotic; Antiplatelet; Atherosclerosis

\section{Mini Review}

It is known that a major part of pharmaceutical compounds that we use today are originated from plants. It is indicative that 157 out of 520 formulations approved in the USA between 1983 and 1994, were natural products [1]. According to an interesting the level of success in plant derived drug discovery for clinical use, raises dramatically [2]. Amongst the plants that are under relevant research, especially regarding cardiovascular disease is saffron [3]. The plant was utilized since ancient times (>2000 B.C.), especially at regions of Persia and India. At the same period, it was used in Greece, as observed at some well-known wall paintings at Knossos and Santorini. The evaluation of its healing properties during the Classical period is summarized in the relevant reference of Dioskorides, "saffron is very potent at its medical use" [4]. Nowadays' research started approximately 40 years ago and peaked during the last decade with a multitude of theses, mainly at experimental level. Lately, some clinical trials have started in depression, Alzheimer's disease, metabolic syndrome and degenerative eye disease [5-8]. It should be noted that it is difficult to decode the pharmaceutical properties of saffron, since sometimes they refer to its whole extract, and sometimes to its main biological constituents: crocin, crocetin and safranal (Figure 1). Research for the antithrombotic effect of saffron mainly focuses on the arterial part. The first who observed that cardiovascular events were less frequent in a region of Spain, probably due to higher consumption of saffron [9]. This resembles the well-known "French paradox" with wine [10]. One year later, the beneficial effect of crocetin in atherosclerosis in mice [11]. This was expected, since there were not relevant theses and findings in support of such a correlation. The research endeavor to this direction was attempted and continued mainly during the last decade, with remarkable results. The intervention of saffron in this case regards the first stage, the start of the arterial damage, as well as the last stage, the creation of platelet thrombus.

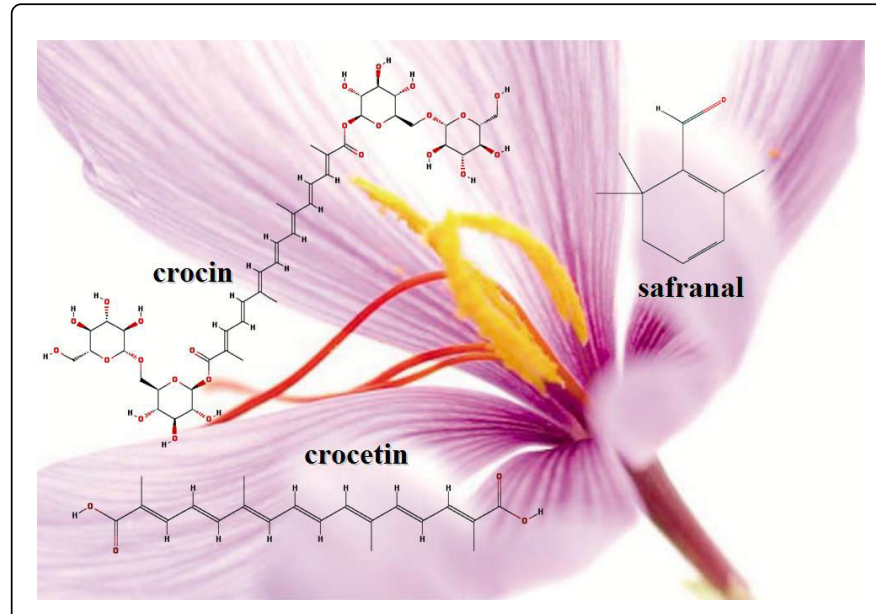

Figure 1: Chemical structure of crocin, crocetin and safranal.

It is current knowledge that the initial biological aberration that leads to atherosclerosis is the oxidation of low density lipoprotein cholesterol (LDL) [12-14].It has been shown that constituents of LDL cause the expression of adhesion molecules in the surface of endothelial cells [12]. Specific adhesion molecules, called "vascular cell adhesion molecules-1, VCAM-1", lead to white blood cells adhesion. Recruitment of mononuclear leucocytes at tunica intima is characteristic of the initial vascular damage [12]. Constituents of saffron interfere at the initial stage, offering protection against oxidation of LDL by means of their potent antioxidative function [15-17]. Recently, it was reported that crocin lowered significantly the levels of intracellular reactive oxygen species (ROS) and also lipid peroxidation. Additionally, they inhibit the expression of cell adhesion molecules and the adhesion of leucocytes to endothelial cells, as well as the angiotensin II induced muscle cell proliferation [18,19]. After the initial damage, the process is known. Briefly, oxidized LDL (OxLDL) will lead to the appearance of foamy cells that together with smooth 
Citation: Sinakosa ZM, Geromichalosb GD (2016) The Effect of Saffron (Crocus sativus) Carotenoids on Hemostasis and Atherosclerosis. Next Generat Sequenc \& Applic 3: 127. doi:10.4172/2469-9853.1000127

Page 2 of 3

muscle cells which migrate to the inner layer, will gradually participate in the formation of the atheromatous plaque. Potential rupture of the plaque is followed firstly by the adhesion of platelets, afterwards by their aggregation, and eventually by the formation of thrombus. So far, medicine intervenes only in the stage of aggregation with the known inhibitors, the "antiplatelet drugs". An in vitro study noted that the extract of saffron inhibits the aggregation of platelets. This effect with the induced inhibition of the secretion of intracellular $\mathrm{Ca}^{2+}[20,21]$.

In silico studies demonstrated that crocetin and picrocrocin have the same binding site with aspirin in cyclooxygenase I (COX-1) (Figure 2). The similar results in an in vitro study. Therefore, it is possible that through this pathway saffron exerts its antiplatelet effect $[22,23]$.

Some interesting findings about the hypolipidemic effects of saffron are presented who attribute these effects to the inhibition of pancreatic lipase by saffron, leading to the malabsorption of cholesterol. Concerning saffron's activity in the blood clotting mechanism, the relevant observations are limited [19]. An in vitro study noted significant increase of prothrombin time and of partial thromboplastin time in the presence of crocin, as well as the inhibition of Xa factor in silico (Figure 3). Administration of saffron at volunteers, 200 and 400 $\mathrm{mg} / \mathrm{d}$ for 7 days, did not lead to increase of prothrombin time and of partial thromboplastin time $[21,24]$. Tsantarliotou et al. in a recent study, observed that administration of crocetin significantly improved the condition of disseminated intravascular coagulation (hematological parameters and kidney fibrosis) in rabbits, after infusion of endotoxin [25].

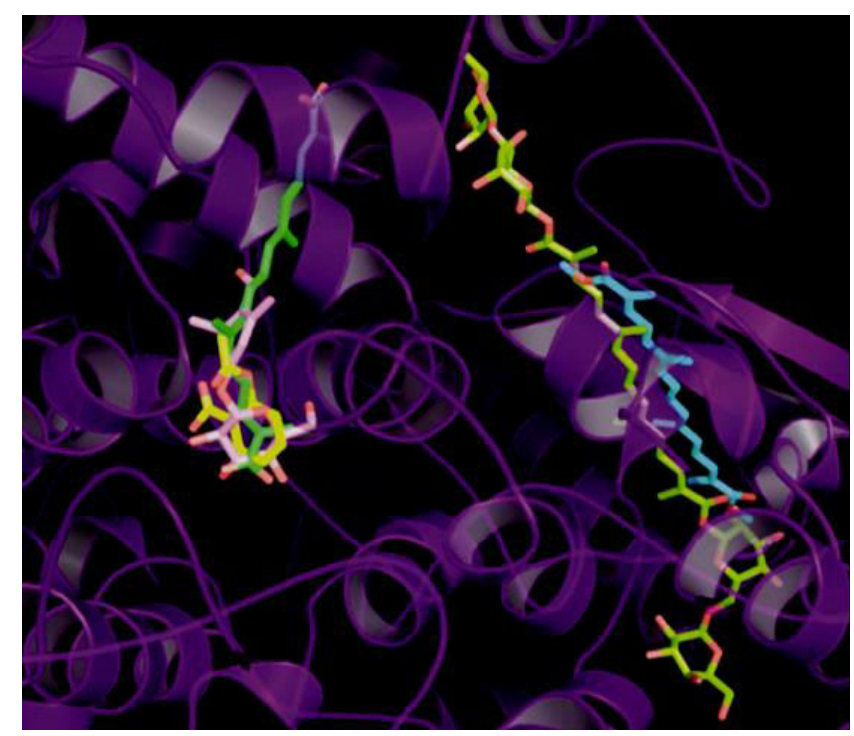

Figure 2: Binding site of aspirin (yellow $\mathrm{C}$ atoms), picrocrocin (pink $\mathrm{C}$ atoms), crocetin (green $\mathrm{C}$ atoms), crocin (light green $\mathrm{C}$ atoms) and dimethylcrocetin (light blue $\mathrm{C}$ atoms) in cyclooxygenase I (COX-1) protein (PDB ID: 1EQG).

The authors attribute the positive outcome to the anticoagulant and mainly the "anti-Xa" effect of saffron [24]. Recently, it has been reported that crocin intervenes in inodolytic system, inhibiting the activity of Plasminogen Activator Inhibitor 1 (PAI1) [26].

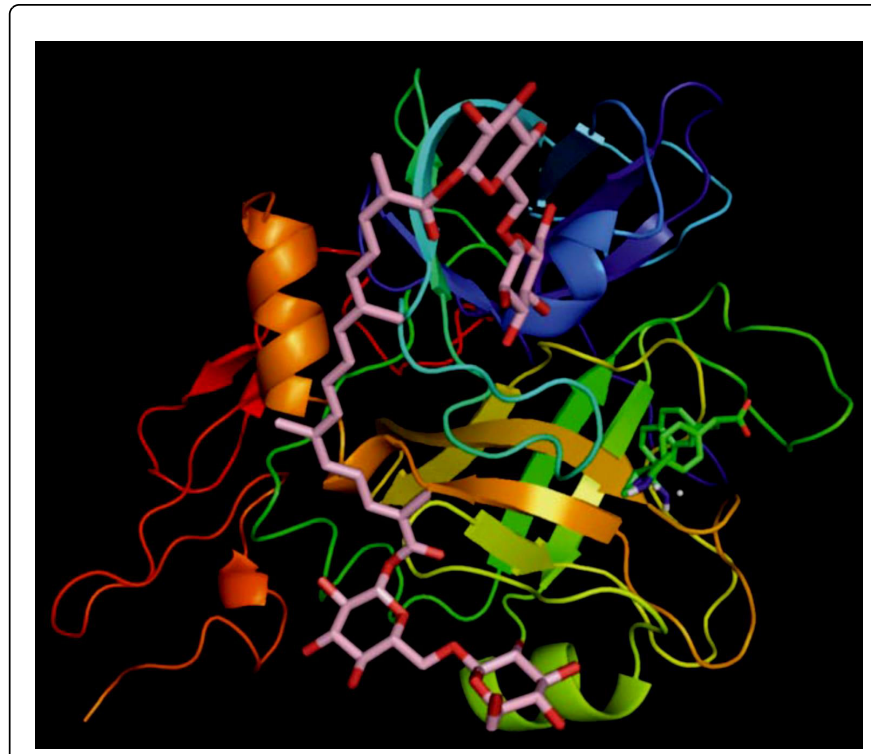

Figure 3: Binding site of crocin (light pink $\mathrm{C}$ atoms) and the known inhibitor DX9(green C atoms) on coagulation factor Xa protein (PDB ID: 1FAX).

As a result, the overall antithrombotic effect of saffron, could be attributed to crocetin's inhibitory effect in the development of experimental hyperlipidemic atherosclerosis in quails and rabbits. It should be especially noted that saffron is non-toxic (a study has shown an LD50 value of $20.7 \mathrm{~g} / \mathrm{Kg}$ ) and has no side effects [15,27-30].

As a summary, it is concluded that saffron exerts antithrombotic effect, especially at the arterial part. This effect, observed at the whole extract as well as individual constituents (crocin, crocetin etc.), obviously shows that saffron presents clinical interest, especially in atherosclerosis.

\section{References}

1. Cragg GM, Newman DJ, Snader KM (1997) Natural products in drug discovery and development. J Nat Prod 60: 52-60.

2. Kumar V (2006) Potential medicinal plants for CNS disorders: An overview. Phytother Res 20: 1023-1035.

3. Mahady G (2011) Medicinal plants for the prevention and treatment of coronary heart disease. Ethnopharmacology Vol II.

4. Dioskourides, Book A, chap. Ke (1st Century AD).

5. Noorbalaa AA, Akhondzadeh S, Tahmacebi-Poura N, Jamshidib AH (2005) Hydro-alcoholic extract of crocus sativus L. versus fluoxetine in the treatment of mild to moderate depression: A double-blind randomized pilot trial. J Ethnopharmacol 97: 281-284.

6. Akhondzadeh S, Shafiee Sabet $M$, Harirchian MH, Togha $M$, Cheraghmakani H, et al.(2010) Saffron in the treatment of patients with mild to moderate Alzheimer's disease:A 16-week, randomized and placebo-controlled trial. J Clin Pharm Ther 35: 581-588.

7. Shemashian M, Mousahj S, Norozy A, Kesmany T, Moghiman T, et al. (2014) Saffron in metabolic syndrome: Its effect on antibody titers to heat shock proteins 27,60, 65 and 70. J Complement Integr Med 11: 43-49.

8. Piccardi M, Maragoni D, Minnella AM, Savastano MC, Falcini D, et al. (2012) A longitudinal follow-up study of saffron supplementation in early age - related macular degeneration. Evidence-Based Complementary and Alternative Medicine. 
Citation: Sinakosa ZM, Geromichalosb GD (2016) The Effect of Saffron (Crocus sativus) Carotenoids on Hemostasis and Atherosclerosis. Next Generat Sequenc \& Applic 3: 127. doi:10.4172/2469-9853.1000127

Page 3 of 3

9. Grisolia S (1974) Hypoxia, saffron and cardiovascular disease. Lancet 2: 41-42.

10. Gainer JL, Jones JR (1975) The use of crocetin in experimental atherosclerosis. Experimentia 31: 548-549.

11. Renaud S, Lergenil M (1992) Wine, alcohol, platelets and the French paradox for coronary heart disease. Lancet 339: 1523-1526.

12. Libby P (2000) Changing concepts in atherogenesis. J Intern Med 247: 349-358.

13. Pirillo A, Norada C, Catapano A (2013) Lox, OxLDL and atherosclerosis. Mediators Inflamm.

14. Steinberg D (1997) Low density lipoprotein oxidation and its pathobiological significance. J Biol Chem 272: 20963-20966.

15. He S, Qian Z, Tang F, Wen N, Xu G, et al. (1995) Effect of crocin on experimental atherosclerosis in quails and its mechanisms. Life Sci 77: 907-921.

16. Assimopoulou AN, Sinakos Z, Papageorgiou VP (2005) Radical scavenging activity of crocus sativus L. extract and its bioactive constituents. Phytother Res 19: 997-1000.

17. Papandreou M, Kanakis CD, Polissiou MG, Efthimiopoulos S, Cordopatis $\mathrm{P}$, et al. (2006) Inhibitory activity in amyloid-b aggregation and antioxidant properties of crocus sativus extract and its crocin constituents. J Agric Food Chem 54: 8762-8768.

18. Sapanidou V, Taitzoglou I, Tsakmakidis I, Kourtzelis I, Fletouris D, et al. (2015) Antioxidant effect of crocin on bovine sperm quality and in vitro fertilization. Theriogenology 84: 1273-1282.

19. Zheng S, Qian Z, Wen N, Xi L (2007) Crocetin suppresses angiotensin II induced vascular smooth-muscle cell proliferation through inhibition of ERK1/2 activation and cell-cycle progression. J Cardiovasc Pharmacol 50: 519-525.

20. Jessie SW, Krishnakantha TP (2005) Inhibition of human platelet aggregation and membrane lipid peroxidation by food spice, saffron. Mol Cell Biochem 278: 59-63.
21. Yang L, Qian Z, Yang Y, Sheng L, Ji H, et al. (2008) Involvement of Ca2+ in the inhibition by crocetin on of platelet activity and thrombosis formation. J Agric Food Chem 56: 9429-9433.

22. Geromichalos G (2013) The effect of saffron's carotenoids in cyclooxygenase I. In silico study. Invited lecture at North Greece Haematologic Society.

23. Xu GL, Li G, Ma HP, Zhong H, Liu F, et al. (2009) Preventive effect of crocin in inflamed animals and in LPS-challenged RAW 264.7 cells. J Agric Food Chem 57: 8325-8330.

24. Ditsa M, Geromihalos G, Tragoulia E, Markala D, Meleti C, et al. (2012) In vitro and in silico study of the effect of crocin and safranal on human plasma coagulation. Thrombosis Research 130: 167.

25. Tsantarliotou M, Poutahidis T, Markala D, Kazakos G, Sapanidou V, et al. (2013) Crocetin administration ameliorates endotoxin-induced disseminated intravascular coagulation in rabbits. Blood Coagul Fibrinolysis 24: 305-310.

26. Tsantarliotou M, Lavrentiadou S, Psalla D, Taitzoglou I, Kritsepi M, et al. (2015) Crocin administration reduces the inactivator activity of the activator of Plasminogen Activator Inhibitor-1 (PAI1) in rats exposed to endotoxin. Haema 6: 35.

27. He SY, Qian ZY, Wen N, Tang FT, Xu GL, et al. (2007) Influence of crocetin on experimental atherosclerosis in hyperlipidemic-diet quails. Eur J Pharmacol 554: 191-195.

28. Zheng S, Qian Z, Sheng L, Wen N (2006) Crocetin attenuates atherosclerosis in hyperlipidemic rabbits through inhibition of LDL oxidation. J Cardiovasc Pharmacol 47:70-76.

29. Abdullaev FI (2002) Cancer chemopreventive and tumoricidal properties of saffron crocus sativus L. Exp Biol Med (Maywood) 227: 20-25.

30. Ramadan A, Soliman G, Sawsan SM, Salw MN, Rehab FA (2012) Evaluation of the safety and antioxidant activities of crocus sativus and propolis ethanolic extracts. Journal of Saudi Chemical Society 16: 13-21. 